\title{
Effect of respiratory muscle strengthening with breathing exercises on Ventilatory functions, aerobic fitness and their association with performance in elite rowers
}

\section{Dilani Priyashanthi Perera ( $\nabla$ dperera85@yahoo.com )}

General Sir John Kotelawala Defence University https://orcid.org/0000-0003-3826-4936

Anoja Ariyasinghe

University of Peradeniya Faculty of Medicine

Anula kariyawasam

University of Peradeniya Faculty of Medicine

\section{Research note}

Keywords: Respiratory muscle training, aerobic fitness, ventilatory parameters, rowing performance

Posted Date: August 3rd, 2020

DOl: https://doi.org/10.21203/rs.3.rs-45337/v1

License: (c) (1) This work is licensed under a Creative Commons Attribution 4.0 International License.

Read Full License 


\section{Abstract}

\section{Objective}

Rowing is one of the most physically demanding endurance sports requiring high levels of ventilation. The aim of this study was to investigate the effect of RMT on ventilatory parameters, aerobic fitness and rowing ergometer performance among 20 professional rowers (experimental $(n=11)$ and control $(n=9)$ aged 20-35 years in Sri Lanka.

Results

Rowers in the experimental group were prescribed a RMT program comprising of breathing exercises while control group was prescribed a general exercise program for a 12 weeks. There were significant improvements in PIF, FVC, and $\mathrm{VO}_{2}$ maxin the experimental group after 12-weeks $(\mathrm{p}<0.05)$ while only $\mathrm{VO}_{2}$ max improved non-significantly in the control group $(p>0.05)$.Compared to the control, PIF improved significantly in the experimental group $(\mathrm{p}<0.05)$. The rowers in the experimental group with higher PIF and $\mathrm{VO}_{2}$ max performed better at $2000 \mathrm{~m}$ and $5000 \mathrm{~m}$ ergometer whereas in the control group, only $\mathrm{VO}_{2}$ max was associated with better performance in $5000 \mathrm{~m}$ ergometer. This suggests that the RMT program had a significant effect in improving some ventilatory parameters and $\mathrm{VO}_{2}$ max of the rowers resulting in better performance.

Trial registration: Current Controlled Trials UMIN000040345, 08/05/2020. "Retrospectively registered"

\section{Introduction}

Rowing is one of the most physically demanding endurance sports requiring high levels of ventilation [1]. Rowing involves not only the locomotor muscles of the body but also the respiratory muscles as well [2]. Rowers have been shown to have very large total lung capacity (TLC), vital capacity (VC) [3] and peak expiratory flows (PEF) $[4,5]$.

Oxygen consumption increases by about 20 -fold from the resting state of $250 \mathrm{ml} / \mathrm{min}$ to $4000 \mathrm{ml} / \mathrm{m}$ during exercise in the well-trained athlete at sub-maximal intensity level [6].The most limiting factor for oxygen uptake during exercise is the pumping ability of the heart compared to the respiratory system [7]. But breathing does limit exercise performance because respiratory muscles enforce their own demands upon the oxygen delivery system [8]. Recent investigations have shown that an increase in respiratory muscle demand during intense exercise reduces the limb blood flow $[9,10]$ by diverting blood flow from limb muscles to the respiratory muscles, the metaboreflex. This accelerates muscle fatigue which has detrimental effects on sports performance $[11,12]$. Therefore, respiratory muscle training (RMT) becomes useful to augment respiratory muscle functions in high intensity sports like rowing [13].Further, it has been shown that improvements in lung functions help to improve exercise performance in trained athletes $[12,14]$. In addition, it is well documented that yoga, which comprises of breathing exercises, improves respiratory parameters $[13,15]$ and respiratory muscle strengthening $[17,18]$. 
RMT can be carried out using many training devises. However, the high cost in purchasing such devises is a drawback for many developing countries like Sri Lanka. This novel RMT program, which included specific exercises for respiratory muscles, was designed to assess its effects on ventilatory parameters, aerobic fitness and performance among professional rowers in Sri Lanka.

\section{Materials And Methods}

A case controlled randomized study was conducted in 20 male rowers aged between 20-35 years during the competitive periodat General Sir John Kotelawala Defence University. Age, body weight and height matched rowers were divided into an experimental $(n=11)$ and a control group $(n=9)$. Prior to data collection, written informed consent was obtained from all rowers. This study was conducted in accordance with the declaration of Helsinki and Ethical Clearance was obtained from Ethics Review Committee, Faculty of Medicine, University of Peradeniya (2016/EC/52). The current research study adheres to the CONSORT guidelines and completed CONSORT checklists are attached in the additional file A.

\section{Data Collection}

Initially, the assessment of lung volumes, capacities and flow rates namely; peak inspiratory flows (PIF), peak expiratory flows (PEF), forced vital capacity (FVC) and forced expiratory volume in 1 second $\left(\mathrm{FEV}_{1}\right)$ were done using a portable spirometer (Spiro analyzer ST-75) in the standing position according to joint American Thoracic Society and European Respiratory Society guidelines [19].Astrand- Ryhming submaximal bicycle ergometer test was used for the determination of aerobic fitness $\left(\mathrm{VO}_{2} \mathrm{max}\right)$ using a Monark cycle ergometer $828 \mathrm{E}$. $\mathrm{VO}_{2}$ max in litres/minute was predicted using standards tables and a nomogram [20]. The test distance of $2000 \mathrm{~m}$ and $5000 \mathrm{~m}$ are commonly used to monitor rowing training and performance. The concept II, (Nottingham, UK) ergometer machine and stopwatch were used for the test and the time spent on the rowing ergometer machine was assessed.

Subsequently, rowers in the experimental group were prescribed aRMT program is included as Additional file 1.The general exercise program followed by the control group includes a full description of general exercise program in Additional file 2.

The RMT program and the general exercise program were conducted for 7 days per week for 12 weeks after which assessment of the lung parameters, $\mathrm{VO}_{2} \mathrm{max}$ and ergometer performance were repeated. During the training program, all participants in both groups were requested to maintain a detailed physical activity-training schedule and an "Exercise program training diary" in order to monitor training adherence.

\section{Statistical analysis}

Data was entered and validated in a SPSS data base. The descriptive statistics were calculated for respiratory parameters, aerobic fitness and rowing ergomtere performance tests in both groups. Changes 
in lung parameters and aerobic fitness were considered as outcome variables. Above measurements were taken prior to the test (pre-test data at first session) and after the test (post test data after 12 weeks of exercise program) in both groups. They were compared before and after the exercise programs in both groups using paired sample t test and between two groups using independent sample t test. The relationship between the two variables was assessed with the Pearson Correlation. Statistical analysis was conducted at a $95 \%$ confidence interval, and $p<0.05$ was considered statistically significant.

\section{Results}

The Mean age of study sample was $25.3 \pm 3.5$ years. Table 1 shows lung parameters namely: PIF, PEF, FVC and $\mathrm{FEV}_{1}$ in the control $(n=9)$ and the experimental groups $(n=11)$ before and after introducing the 12-week non- respiratory muscle and RMT programs respectively. After introducing the RMT program, asignificant difference was observed in PIF and FVC $(p<0.05)$ in the experimental group with no significant difference in other parameters. In contrast, no significant difference was observed in all the respiratory parameters in the control group after introducing the non- RMT program.

Table 1

Lung Volumes, Lung Capacities and Flow Rats of the Rowers in the Control $(n=9)$ and Experimental Group $(n=11)$ before and after 12-week Exercise Programs

\begin{tabular}{|c|c|c|c|c|c|c|}
\hline \multirow[t]{3}{*}{ Lung Parameters } & \multirow{2}{*}{\multicolumn{3}{|c|}{$\begin{array}{l}\text { Control group } \\
\text { Mean } \pm \text { SD }\end{array}$}} & \multirow{2}{*}{\multicolumn{3}{|c|}{$\begin{array}{l}\text { Experimental group } \\
\text { Mean } \pm \text { SD }\end{array}$}} \\
\hline & & & & & & \\
\hline & $\begin{array}{l}\text { Pre } \\
\text { training }\end{array}$ & Post training & $p$ value & $\begin{array}{l}\text { Pre } \\
\text { training }\end{array}$ & $\begin{array}{l}\text { Post } \\
\text { training }\end{array}$ & $\begin{array}{l}\mathrm{p} \\
\text { value }\end{array}$ \\
\hline PIF (L/s) & $10.2 \pm 0.6$ & $10.5 \pm 0.6$ & 0.64 & $10.0 \pm 0.8$ & $11.8 \pm 0.9$ & $0.001 * \star$ \\
\hline PEF (L/s) & $10.8 \pm 1.4$ & $11.2 \pm 0.9$ & 0.52 & $11.0 \pm 3.0$ & $11.4 \pm 1.2$ & 0.56 \\
\hline FVC (L) & $5.4 \pm 1.3$ & $5.3 \pm 1.3$ & 0.31 & $5.2 \pm 1.6$ & $6.3 \pm 1.3$ & $0.04^{*}$ \\
\hline $\mathrm{FEV}_{1}(\mathrm{~L})$ & $5.8 \pm 1.1$ & $5.7 \pm 1.4$ & 0.31 & $5.6 \pm 1.2$ & $6.0 \pm 0.9$ & 0.15 \\
\hline
\end{tabular}

At the end of 12 -week training program: PIF, PEF, FVC and FEV 1 were compared between the control and the experimental groups are shown in the Table 2. A significant increase was observed in PIF and FVC in the experimental group compared to the control group $(p<0.05)$ while there was no significant difference in PEF and $\mathrm{FEV}_{1}$. 
Table 2

Comparison of Lung Volumes, Lung Capacities and Flow Rates between the Control $(n=9)$ and the Experimental Group $(n=11)$ after the Respective Training Programs

\begin{tabular}{|c|c|c|c|}
\hline \multirow[t]{2}{*}{ Lung volumes, capacities and flow rates } & \multicolumn{2}{|l|}{ Mean \pm SD } & \multirow[t]{2}{*}{$\mathrm{p}$ value } \\
\hline & $\begin{array}{l}\text { Control } \\
\text { group }\end{array}$ & Experimental group & \\
\hline $\mathrm{PIF}(\mathrm{L} / \mathrm{s})$ & $10.5 \pm 0.6$ & $11.8 \pm 0.9$ & $0.04^{*}$ \\
\hline PEF (L/s) & $11.2 \pm 0.9$ & $11.4 \pm 1.2$ & 0.22 \\
\hline FVC (L) & $5.3 \pm 1.3$ & $6.3 \pm 1.3$ & $0.04 *$ \\
\hline $\mathrm{FEV}_{1}(\mathrm{~L})$ & $5.7 \pm 1.4$ & $6.0 \pm 0.9$ & 0.27 \\
\hline
\end{tabular}

Figure $\mathrm{S} 1$ reflects the aerobic fitness in the control and the experimental groups before and after the 12 weeks respective training programs. The experimental group showed $2 \%$ significant improvement $(p<$ $0.05)$ in aerobic fitness while the improvement in the control group was $1 \%$ which was not significant ( $p>$ $0.05)$. However, there was no statistically significant difference in the improvement in aerobic fitness between the control and the experimental groups after the respective training programs $(p>0.05)$.

Table 3 shows the relationship of respiratory parameters, aerobic fitness and $2000 \mathrm{~m}$ and $5000 \mathrm{~m}$ rowing ergometer performance in both groups. In the experimental group, all the respiratory parameters showed negative correlation with both the $2000 \mathrm{~m}$ and 5000 m ergometer performance, while only PIF showed a significant relationship with $2000 \mathrm{~m}$ ergometer performance test $(r=-0.69 ; p=0.02)$. In the control group, PEF and FEV 1 showed negative correlations while PIF and FVC showed a positive correlation with $2000 \mathrm{~m}$ and 5000 m ergometer tests however they were insignificant. 
Table 3

The relationship between respiratory parameters and aerobic fitness with the ergometre performance in the control group $(n=9)$ and the experimental group $(n=11)$

\begin{tabular}{|c|c|c|c|c|c|c|c|c|}
\hline \multirow{3}{*}{$\begin{array}{l}\text { Flow volumes, lung } \\
\text { capacities and flow } \\
\text { rates }\end{array}$} & \multicolumn{2}{|c|}{$\begin{array}{l}\text { Control group } \\
\text { Mean } \pm \text { SD }\end{array}$} & & & \multicolumn{4}{|c|}{$\begin{array}{l}\text { Experimental group } \\
\text { Mean } \pm \text { SD }\end{array}$} \\
\hline & \multicolumn{2}{|c|}{$\begin{array}{l}2000 \mathrm{~m} \\
\text { ergometre } \\
\text { performance }\end{array}$} & \multicolumn{2}{|c|}{$\begin{array}{l}5000 \mathrm{~m} \\
\text { ergometre } \\
\text { performance }\end{array}$} & \multicolumn{2}{|c|}{$\begin{array}{l}2000 \mathrm{~m} \\
\text { ergometre } \\
\text { performance }\end{array}$} & \multicolumn{2}{|c|}{$\begin{array}{l}5000 \mathrm{~m} \\
\text { ergometre } \\
\text { performance }\end{array}$} \\
\hline & $\mathbf{r}$ & p & $\mathbf{r}$ & $\mathbf{p}$ & $\mathbf{r}$ & $\mathbf{p}$ & $r$ & $\mathbf{p}$ \\
\hline PIF (L/s) & -0.05 & 0.88 & 0.14 & 0.72 & -0.69 & $0.02 *$ & -0.09 & 0.79 \\
\hline PEF (L/s) & -0.37 & 0.33 & -0.57 & 0.11 & -0.01 & 0.99 & -0.22 & 0.52 \\
\hline FVC (L) & 0.12 & 0.76 & -0.51 & 0.17 & -0.43 & 0.18 & -0.08 & 0.82 \\
\hline $\mathrm{FEV}_{1}(\mathrm{~L})$ & -0.12 & 0.76 & -0.61 & 0.08 & -0.28 & 0.39 & -0.02 & 0.96 \\
\hline Aerobic fitness & -0.06 & 0.88 & -0.68 & $0.04 *$ & -0.77 & $0.00 \star \star$ & -0.67 & $0.04^{\star}$ \\
\hline
\end{tabular}

Aerobic fitness showed a significant negative correlations between and both the $2000 \mathrm{~m}(\mathrm{r}=-0.77 ; \mathrm{p}<$ $0.01)$ and $5000 \mathrm{~m}$ ergometer performance test $(r=-0.67 ; p<0.05)$ in the experimental group while in the control a significant negative correlation was observed only with the $5000 \mathrm{~m}$ ergometer performance test $(r=-0.68 ; p<0.05)$.

\section{Discussion}

Lung volumes, capacities and flow rates have been observed to be greater in high-intensity endurance sports like rowing, cycling, boxing, football, basketball, rugby and water polo in comparison to power, mixed and skill groups of sports [23]. In addition, studies have shown that elite rowers require extremely high levels of ventilation with them showing higher ventilatory parameters $[3,4]$.

In the present study, when comparing the pre and post-training values of ventilatory parameters, it was observed that PIF and FVC improved significantly in the experimental group $(p<0.05)$ while no improvements were observed in all lung parameters in the control group $(p>0.05)$ after the respective training programs (Table 1). Furthermore, PIF was significantly higher $(p=0.04)$ in the experimental group compared to the control group after the 12 weeks RMT program (Table 2). Several past studies have also shown similar findings with improvement in PIF following RMT using the RMT device [24, 25].PIF is known to be the fastest flow rate achieved during a maximum inspiration and provides a measure of the maximal contraction of the inspiratory muscles [26]. 
The novel RMT training program conducted in this study included profound (deep) inspirations and inspiratory hiccups, exercises that strengthen the inspiratory muscles, while isometric side bridge, curls ups improved expiratory muscles strength. In addition, it also included flexibility training to stretch the chest wall. These techniques would have helped to strengthen the respiratory muscles, improve the lung capacity (FVC) and PIF and increase chest expansion in the experimental group compared to the control group. These exercises have similarities with deep breathing techniques used in pranayama yoga practice during which the respiratory muscles are stretched fully towards the chest wall represented by increased chest wall expansion together with increased lung volumes, capacities and flow rates namely FVC, FEV ${ }_{1}$ and PEF in healthy subjects $[13,27,28]$. Long term benefits of yoga has been shown to increase chest expansion, breath-holding time and PEF $[28,29]$.

Healthy respiratory systems are anatomically well equipped to meet the oxygen requirements at rest and during increased exercise intensities. In the present study, significant improvement was seen in $\mathrm{VO}_{2}$ maxovertime in both groups with only the experimental group showing significant improvements. No significant difference was observed in $\mathrm{VO}_{2}$ maxbetween the two groups after the RMT program $(p>0.05)$. Many studies have examined the effect of $\mathrm{RMT}$ on $\mathrm{VO}_{2}$ maxin different sports and revealed that $\mathrm{VO}_{2} \mathrm{max}$ was not altered by RMT while a small group of studies have shown a statistically significant decrease in sub-maximal $\mathrm{O}_{2}$ following RMT across different sports $[25,30]$.

When considering the relationship between ventilatory functions and performance it was observed that there was a negative relationship between lung functions and $2000 \mathrm{~m}$ and $5000 \mathrm{~m}$ ergometer performance in both groups in the present study. However, only PIF significantly correlated with $2000 \mathrm{~m}$ performance in experimental group. This indicates that higher PIF are associated with lower ergometer time performance. However, contradictory outcomes have been observed concerning the relationship of ventilatory functions with sports performance following RMT. One study in athletes' documented that there was a significant negative relationship with FVC and running times [31] while in another study done on cyclists observed improvements in cycle endurance time subsequent with improved ventilatory functions following RMT [32].

When considering aerobic fitness, the present study revealed that there was a significant negative correlation between $\mathrm{VO}_{2} \mathrm{max}$, and $2000 \mathrm{~m}$ and $5000 \mathrm{~m}$ ergometer performance test in the experimental group $(r=-0.68 ; p<0.05)$ (Table 3 ) while in the control group only $2000 \mathrm{~m}$ performance was significant. Similarly, several past studies have reported a significant correlation between $2000 \mathrm{~m}$ ergometer rowing performance and $\mathrm{VO}_{2}$ max values $[33,34]$. However, another study stated that no significant correlation exists between aerobic fitness and 2000 meter ergometer performance in both male and female rowers [35]. Though past research has consistently demonstrated that success in rowing is associated with higher $\mathrm{VO}_{2}$ max, some studies stated that $\mathrm{VO}_{2}$ max alone is not a good predictor of rowing performance in rowers with similar endurance capacity $[4,33]$.

The effect of RMT on lung functions and exercise performance has been inconclusive because of the differences in research design such as inappropriate performance outcome variables, ineffective RMT 
protocols, small sample sizes and the lack of carefully matched experimental and placebo groups [35]. Some studies have suggested that a well-designed case-controlled study with an appropriate RMT protocol [36] and self-motivation of athletes also contributes to a positive impact on exercise performance [8,24,].

Overall, our findings suggested that applying this novel RMT program in the training schedules of rowers resulted in improving some respiratory functions (PIF) and aerobic fitness and these were associated with greater performance in both $2000 \mathrm{~m}$ and $5000 \mathrm{~m}$ rowing ergometer tests. This highlights the importance of introducing RMT in training protocols of sportsmen and women in Sri Lanka, in addition to peripheral muscle training program, as a routine practice to improve the sports performance. This novel RMT could also be used in rehabilitation of clinical populations, especially in developing countries, as RMT devices are costly and inaccessible for many.

\section{Limitations}

To the authors' knowledge, it is the first time that the Sri Lankan rowers have been introduced to RMT they had lack of awareness about RMT which would have resulted in insufficient self-motivation to follow the training schedule daily. The present study alsois limited to male rowers. Female rowers have weaker respiratory muscles than male rowers and that RMT may benefit female rowers more than male rowers.

\section{Abbreviations}

FEV $_{1}$ : Forced Expiratory Volume in one second; FVC: Forced Vital Capacity ;PEF: Peak Expiratory Flow; PIF: Peak Inspiratory Flow and RMT: Respiratory Muscle Training

\section{Declarations}

\section{Ethics approval and consent to participate}

This study adhered to ethical guidelines under the Declaration of Helsinki. Institutional permission to conduct the study was taken at the General Sir John Kotelawala Defence University and Exercise and Sport laboratory, Faculty of Medicine, University of Peradeniya, Sri Lanka. Ethical Clearance was obtained from Ethics Review Committee, Faculty of Medicine, University of Peradeniya (2016/EC/52). Participants provided written informed consent prior to participation following a verbal explanation and reading an information sheet explaining the rationale and all measurements, testing and respective training programs regarding the study.

\section{Consent for publication}

Not applicable as the manuscript does not contain any data from any individual person. 
Availability of data and materials

The datasets used and/or analysed during the current study are available from the corresponding author on reasonable request.

\section{Competing interests}

The authors declare that they have no competing interests.

\section{Funding}

This study did not have funding. The principal investigator self funded in the design of the study and collection, analysis, and interpretation of data and in writing the manuscript.

\section{Authors' contributions}

ADP, AR and AK originally developed the concept and the design of the study. ADP is a M.Phil student and this manuscript is a part of her M.Phil thesis. ADP is the principal investigator under the guidance and supervision of AR and AK. ADP conducted the literature review, data collection and analyzed the data with variable assistance coming from other people who were acknowledged in the acknowledgment section. ADP drafted the manuscript for publication and acted as the corresponding author. AR and AK acted upon critical revision of the manuscript, statistical input, and provided extensive revisions prior to submission to the journal for review. All the authors read and approved the final version of the manuscript before submission.

\section{Acknowledgements}

The authors would like to acknowledge all the rowers who participated in the study for their fullest cooperation and contribution. We are grateful for the support we have received during data collection from the technical staff of the Exercise and Sports Science laboratory, Department of Physiology, Faculty of Medicine, University of Peradeniya and Gymnasium, General Sir John Kotelawala Defence University. Further, we would like to thank Mr. P. Dias, Senior Lecturer, University of Sri Jayewardenepura who assisted us in statistical analysis of data.

\section{References}

1. Dunbar J. Get out of the gym and onto the water. Peak Performance. 1994;43:2-4.

2. Secher NH. Physiological and biomechanical aspects of rowing: Implications for training. Sports Med. 1993;15:25-42. 
3. Donnelly PM, Ellis ER, Keating JM, Keena VA, Woolcock AJ, Bye PTP. Lung function of rowers. The Australian Journal of Science Medicine in Sport. 1991;232:42-6.

4. Steinacker JM, Both M, Whipp BJ. Pulmonary mechanics and entrainment of respiration and stroke rate during rowing. International Journal of Sports Medicine. 1993;14:15-9.

5. De Troyer A, Kirkwood PA, Wilson T. Respiratory action of the intercostal muscles. Physiology Review. 2005;85:717-56.

6. Joyner MJ, Casey DP. Regulation of increased blood flow (hyperemia) to muscles during exercise: a hierarchy of competing physiological needs. Physiol Rev. 2015;95(2):549-601.

7. David B, Edward TH. Limiting factors for maximum oxygen uptake and determinants of endurance performance. Med Sci Sports Exerc. 2000;32(1):70-84.

8. Griffiths LA, McConnell AK. The influence of inspiratory and expiratory muscle training upon rowing performance. Eur J Appl Physiol. 2007;99(5):457-66.

9. Harms CA, Babcock MA, McClaren SR, Pegelow DF, Nickele GA, Nelson WB, Dempsey JA. Respiratory muscle work compromises leg blood flow during maximal exercise. J Appl Physiol. 1997;825:157383.

10. Sheel AW, Derchak PA, Pegelow DF, Dempsey JA. Threshold effects of respiratory muscle work on limb vascular resistance. American Journal of Physiology: Heart Circulation Physiology. 2002;282:732-8.

11. McConnell AK, Lomax M. The influence of inspiratory muscle work history and specific inspiratory muscle training upon human limb muscle fatigue. Journal of Physiology. 2006;577:445-55.

12. Harms CA, Wetter T, St Croix CM, Pegelow DF, Dempsey JA. Effects of respiratory muscle work on exercise performance. J Appl Physiol. 2000;89:131-8.

13. Prakash S. Meshram S, Ramtekkar U. Athletes, yogis and individuals with sedentary lifestyles; do their lung functions differ? Indian J PhysiolPharmacol. 2007;51:76-80.

14. Boutellier U, Piwko P. The respiratory system as an exercise limiting factor in normal sedentary subjects. European Journal of Applied Physiology Occupational Physiology. 1992;642:145-52.

15. Joshi LN, Joshi VD, Gokhale LV. Effect of short term 'Pranayam' practice on breathing rate and ventilatory functions of lung. Indian J PhysiolPharmacol. 1992;36:105-8.

16. Makwana K, Khirwadkar N, Gupta HC. Effectof short term yoga practice on ventilatory function tests. Indian J PhysiolPharmacol. 1988;32(3):202-8.

17. Madanmohan L, Udupa K, \&Bhavanani AB. Effect of yoga training on handgrip, respiratory pressures and pulmonary function. Indian J PhysiolPharmacol. 2003;47(4):387-92.

18. Miller MR, Hankinson J, Brusasco V, Burgos F, Casaburi R, Coates A, Crapo R, Enright P, Van Der Grinten C, Gustafsson P. Standardisation of spirometry. Eur Respir J. 2005;26:319-38.

19. Astrand. Prediction of maximum oxygen uptake from Herat rate and work load on a Bi-cycle Ergometer (from a nomogram by Astrand. Acta Physio/ Scane. 1960;49(suppl):169): 45-60. 
20. Lazovic B, Mazic S, Suzic-Lazic J, Djelic M, Djordjevic-Saranovic S, Durmic T. Respiratory adaptations in different types of sport. Eur Rev Med Pharmacol Sci. 2015;19(12):2269-74.

21. Thomas D, Fahey Paul M, Insel Walton T. Roth. Fit \& Well Core Concepts and LABS in Physical Fitness and Wellness. 2005; 6-186.

22. Porter SB. Management of respiratory disease, fifteen edition; Tidy's Physiotherapy. 2013; 83-127.

23. Hagerman FC, Connors MC, Gault JA, Hagerman GR, Polonski WJ. Energy expenditure during simulated rowing. Journal of Applied Physiology. 1978;451:87-93.

24. Edwards AM, Cooke CB. Oxygen uptake kinetics and maximal aerobic power are unaffected by inspiratory muscle training in healthy subjects where time to exhaustion is extended. European Journal of Applied Physiology. 2004;93(2):139-44.

25. Nicks CR, Morgan DW, Fuller DK, Caputo JL. The influence of respiratory muscle training upon intermittent exercise performance. International Journal of Sports Medicine. 2004;30(1):16-21.

26. Agostoni E, Fenn WO. Velocity of shortening as a limiting factor in respiratory air flow. Journal of Applied Physiology. 1960;15:349-53.

27. Sivakumar G, Prabhu K, Baliga R, Pai MK, Manjunatha S. Acute effects of deep breathing for a short duration (2-10 minutes) on pulmonary functions in healthy young volunteers. Indian J PhysiolPharmacol. 2011;55:154-59.

28. Subbalakshmi NK, Saxena SK, Urmimala-Urban JAD. Immediate effect of nadishodhana pranayama on some selected parameters of cardiovascular, pulmonary and higher functions of brain. Thai Journal of Physiological Sciences. 2005;18(2):10-6.

29. Ramirez-Sarmiento A, Orozco-Levi M, Guell R, Barriero E, Hernandez N, Mota S, Sangenis M, BroquetasCasan P, Gea J. Inspiratory muscle training in patients with chronic obstructive pulmonary disease: structural adaptation and physiologic outcomes. American Journal of Respiratory Critical Care Medicine. 2002;166:1491-7.

30. Cosgrove MJ, Wilson J, Watt D, Grant SF. The relationship between selected physiological variables of rowers and rowing performance as determined by a $2000 \mathrm{~m}$ ergometer test. Journal of Sports Sciences. 1999;17(11):845-52.

31. Yoshiga CC, Higuchi M. Rowing performance of female and male rowers. Scandinavian Journal of Medicine Science in Sports. 2003;13:317-21.

32. Kaufmann DA, Swenson EW, Fencl J, Lucas A. Pulmonary function of marathon runners. Med Sci Sports Exer. 1974;6:114-7.

33. Inbar O, Weiner P, Azgad Y, Rotstein A, Weinstein Y. Med Sci Sports Exer. 2000;32:1233-7.

34. Perera ADP, Ariyasinghe AS, Makuloluwa PTR. Relationship of Competitive Success to the Physique of Sri Lankan Rowers. American Journal of Sports Science Medicine. 2015;3(3):61-5.

35. McConnell AK, Romer L. Respiratory muscle training in healthy humans: resolving the controversy. Int J Sports Med. 2004;25:284-93.

36. Hopkins WG. How to interpret changes in an athletic performance test. Sportscience. 2004;8:1-7. 


\section{Supplementary Files}

This is a list of supplementary files associated with this preprint. Click to download.

- AdditinalFileA..docx

- Figures1.docx

- Additionalfile2.docx

- Additionalfile1.docx 